\title{
CARACTERÍSTICAS FÍSICAS E MECÂNICAS DE MISTURAS DE SOLO, CIMENTO E CASCA DE ARROZ
}

\begin{abstract}
ANA P. S. MILANI ${ }^{1}$, WESLEY J. FREIRE ${ }^{2}$
RESUMO: Na presente pesquisa, estudaram-se os efeitos da adição da casca de arroz nas propriedades físico-mecânicas da mistura de solo-cimento, visando a obter composições de solocimento-casca de arroz com potencialidade para fabricação de materiais alternativos de construção. Foram realizados o fracionamento, o peneiramento e o pré-tratamento em solução de cal da casca de arroz. Foram determinadas as características físicas do solo e da casca de arroz, sendo executados ensaios de dosagem das misturas de solo-cimento-casca de arroz, aplicando-se às mesmas os ensaios de compactação normal de Proctor e o de compressão simples. Posteriormente, as composições de solo-cimento-casca de arroz foram submetidas aos ensaios de compressão simples e de tração na compressão diametral, aos 7 e aos 28 dias de idade, e de absorção d'água. Depois de determinadas as principais características físicas e mecânicas, pôde-se concluir que as misturas de solo + teor de $12 \%$ de combinações de cimento e casca de arroz se apresentaram como materiais promissores para a fabricação de elementos construtivos, a serem utilizados em construções e instalações rurais.
\end{abstract}

PALAVRAS-CHAVE: resíduo agroindustrial, solo estabilizado, material alternativo.

\section{PHYSICAL AND MECHANICAL CHARACTERISTICS OF SOIL-CEMENT AND RICE HUSK MIXTURES}

\begin{abstract}
The main objective of this work is the study of the effect of rice husk addition on the physical and mechanical properties of soil-cement, in order to obtain an alternative construction material. The rice husk preparation consisted of grinding, sieving, and the pre-treatment with lime solution. The physical characteristics of the soil and of the rice husk were determined. Different amounts of soil, cement and rice husk were tested by compaction and unconfined compression. The specimens molded according to the treatments applied to the mixtures were subsequently submitted to compression testing and to tensile splitting cylinder testing at 7 and 28 days of age and to water absorption testing. After determining its physical and mechanical characteristics, the best results were obtained for the soil $+12 \%$ (cement + rice husk) mixture. The results showed a promising use as an alternative construction material.
\end{abstract}

KEYWORDS: agricultural and industrial residues, soil stabilization, alternative construction material.

\section{INTRODUÇÃO}

Com a utilização racional dos recursos naturais, o resgate do uso do solo como material de construção tem se intensificado ultimamente, tendo seu comportamento físico-mecânico melhorado por meio da estabilização com aglomerantes minerais. Na estabilização do solo com o cimento, ocorrem reações de hidratação dos silicatos e aluminatos presentes no cimento, formando um gel que preenche parte dos vazios da massa e une os grãos adjacentes do solo, conferindo-lhe resistência inicial; paralelamente, ocorrem reações iônicas que provocam a troca de catíons das estruturas argilominerais do solo com os íons de cálcio provenientes da hidratação do cimento adicionado. Além dessas modificações iniciais, ABIKO (1980) afirmou que, ao longo do tempo, formam-se compostos

\footnotetext{
${ }^{1}$ Eng $^{\mathrm{a}}$ Civil, pós-graduanda, FEAGRI/UNICAMP, Campinas - SP, Fone: (0XX19) 3788.1050, ana.silva@ agr.unicamp.br

${ }^{2}$ Professor Tirular, FEAGRI/UNICAMP, Campinas - SP.

Recebido pelo Conselho Editorial em: 2-8-2004

Aprovado pelo Conselho Editorial em: 16-11-2005 
cimentantes que contribuem para o melhoramento de propriedades do material (resistência mecânica, durabilidade, estabilidade volumétrica).

Segundo a ABCP (1985), os solos mais adequados para a fabricação de elementos construtivos de solo-cimento são os que possuem as seguintes características: granulometria desuniforme, sendo $100 \%$ do solo passante na peneira $4,8 \mathrm{~mm}$ e 10 a $50 \%$ passante na peneira $0,075 \mathrm{~mm}$; limite de liquidez menor ou igual a $45 \%$ e índice de plasticidade menor ou igual a 18\%. As propriedades físicomecânicas (resistência à compressão e absorção d'água, por exemplo) do sistema solo-cimento compactado estão intimamente relacionadas com as condições de cura (umidade e temperatura) e compactação. Deve-se trabalhar com umidade de moldagem em torno do teor ótimo, pois quanto mais denso o sistema, maior a sua resistência (PICCHI et al., 1990).

FERREIRA (2003) estudou a resistência à compressão simples e a absorção d'água do material solo-cimento por meio da determinação experimental em corpos-de-prova cilíndricos. O solo utilizado foi de características arenosas $\left(\mathrm{A}_{2-4}\right)$, sendo adicionado ao solo o teor de $10 \%$ de cimento Portland. Os resultados encontrados pelo autor para resistência à compressão simples e absorção de água de corposde-prova foram, em média, respectivamente, 2,0 $\mathrm{MPa}$ e 12\%, aos 7 dias de idade.

Ainda concentrada na fabricação de material de menor impacto ambiental, a utilização conjunta de resíduos vegetais, como a casca de arroz e matrizes cimentantes, tem-se revelado uma alternativa em potencial. SILVEIRA et al. (1996) definiram a casca de arroz como sendo uma capa lenhosa oca, dura e altamente silicosa, composta por $50 \%$ de celulose, $30 \%$ de lignina e $20 \%$ de sílica, em base anidra. Sob o aspecto econômico e tecnológico, a casca de arroz viabiliza a confecção de materiais de baixo custo, pois atua como material de enchimento ou até mesmo de substituição parcial da matériaprima (agregado miúdo) utilizada em materiais de construção convencionais. Já sob o aspecto ambiental, a utilização da casca de arroz permite o controle e a minimização do descarte, do lançamento ou da queima indiscriminada.

ZUCCO (1999) submeteu diferentes frações de casca de arroz a alguns tratamentos para minimizar a incompatibilidade química entre a matriz cimentante e a biomassa vegetal, visando à fabricação de placas de compósito à base de cimento Portland e casca de arroz. Após prensagem e cura das placas, essas foram submetidas a ensaios de compressão paralela, tendo os dados obtidos mostrado que os melhores resultados foram alcançados pelos compósitos fabricados com partículas de casca de arroz lavadas em solução de cal. Esse tratamento permitiu a remoção de extrativos que solubilizam na água e inibem a hidratação do cimento.

A presente pesquisa reveste-se de especial importância porque envolve o estudo de misturas de solo-cimento-casca de arroz para possível utilização em elementos construtivos. Buscam-se, igualmente, condições de minimizar a possível degradação ambiental quando aqueles materiais são produzidos a partir do aproveitamento de resíduos agrícolas e/ou agroindustriais.

\section{MATERIAL E MÉTODOS}

Foram utilizados os seguintes materiais: casca de arroz, coletada em máquina beneficiadora, localizada no município de Itu - SP; dois tipos de solo, sendo um pertencente à classe textural argilosa e outro à classe arenosa; os aglomerantes cimento Portland CP-III-40 RS, da marca Nassau, e cal hidratada CH-III, da marca Minercal. As características físico-químicas do cimento e da cal seguiram, respectivamente, a NBR 5735 (ABNT, 1991) e a NBR 7175 (ABNT, 1992a). Para a determinação das resistências mecânicas, foi utilizada uma prensa universal, da marca Dynatest, com dispositivo de controle de carregamento e capacidade de $200.000 \mathrm{kN}$.

A avaliação estatística foi realizada por meio da análise de variância, com delineamento experimental inteiramente casualizado, em esquema fatorial, e da aplicação do teste de Tukey para 
comparação das médias, a 5\% de probabilidade. Em todo o trabalho, foram feitas três repetições para cada mistura de solo-cimento-casca de arroz.

\section{Preparo e caracterização física da casca de arroz}

A casca de arroz, tão logo recebida no Laboratório de Ensaio de Materiais da Faculdade de Engenharia Agrícola da UNICAMP, passou pelo processo de trituração em moinho de martelo da marca Trapp e peneiramento para a eliminação dos finos, uniformização e melhoria da adesão da casca de arroz ao sistema solo-cimento. A fração utilizável de casca de arroz ficou compreendida entre 4,8 e $0,42 \mathrm{~mm}$ de aberturas de malha. Depois desse processo, a casca foi imersa em solução de cal concentrada a 5\%, por um período de $24 \mathrm{~h}$, pois, conforme recomendações de ZUCCO (1999), esse pré-tratamento minimizou a incompatibilidade química entre a biomassa vegetal e o cimento Portland. Após esse período, a casca passou por lavagem em água corrente e secagem ao ar livre. Então, determinaram-se sua massa unitária, umidade e distribuição em tamanho.

\section{Caracterização física dos solos}

Os solos foram submetidos a ensaios de caracterização para determinar seus principais índices físicos, a saber: análise granulométrica (ABNT, 1984a), limites de liquidez (LL) (ABNT, 1984b) e de plasticidade (LP) (ABNT, 1984c), índice de plasticidade (IP) e massa específica dos sólidos $\left(\gamma_{\mathrm{s}}\right)$ (ABNT, 1982).

\section{Procedimentos aplicados às misturas de solo-cimento-casca de arroz}

Com o objetivo de adicionar a máxima quantidade de casca de arroz e diminuir o consumo de cimento na mistura solo-cimento-casca de arroz, adotaram-se, para estudos de dosagem, as seguintes composições (\% em relação à massa do solo seco): teores de $8 \%$ e $12 \%$ da combinação de cimento e casca de arroz a serem adicionados ao solo arenoso; e teores de $8 \%, 12 \%, 14 \%$ e $18 \%$ da combinação de cimento e casca de arroz a serem adicionados ao solo argiloso. Nas combinações, os teores de cimento e de casca variaram desde $100 \%$ de aglomerante e $0 \%$ de casca, até $60 \%$ de aglomerante e $40 \%$ de casca em incrementos de $10 \%$. Porcentagens maiores de casca de arroz afetaram negativamente a trabalhabilidade e a compactação da mistura.

Para todos os ensaios aplicados às diferentes misturas de solo-cimento-casca, as quantidades predeterminadas dos componentes foram misturadas manualmente, sendo primeiramente misturados o cimento e o solo, e depois a casca, até conseguir homogeneidade, e, por último, adicionou-se a água.

Partindo-se dessas misturas de solo-cimento-casca de arroz, foram executados ensaios de compactação de Proctor (ABNT, 1992b), sendo determinadas a umidade ótima $\left(\mathrm{h}_{\mathrm{ot}}\right)$ e a massa específica aparente seca máxima $\left(\gamma_{\max }\right)$ de cada mistura. Utilizando-se desses parâmetros, foram confeccionados, para cada mistura, corpos-de-prova de $127 \mathrm{~mm}$ de altura e $100 \mathrm{~mm}$ de diâmetro, moldados de acordo com a NBR 12024 (ABNT, 1992c). Depois de 7 dias de cura em câmara úmida, os corpos-de-prova foram submetidos ao ensaio de compressão simples aos 7 dias de idade, conforme norma NBR 12025 (ABNT, 1990), sendo excluída a fase de imersão dos corpos-de-prova em água, antes do rompimento. Esse procedimento foi adotado apenas para a obtenção de dados preliminares.

Após essa avaliação preliminar, as misturas de solo-cimento-casca de arroz escolhidas para fins de caracterização físico-mecânica foram as que apresentaram maior quantidade de casca incorporada, com valor preliminar de resistência à compressão simples maior que $1,5 \mathrm{MPa}$, pois esse valor foi considerado o mínimo necessário para que a mistura solo-cimento-casca fosse aceitável, em termos de resistência mecânica, como elemento construtivo. A escolha desse critério baseou-se nos estudos de NEVES (1988) sobre o uso do sistema solo-cimento em componentes construtivos. A referida autora concluiu que a resistência à compressão do solo-cimento deveria ser igual ou maior que 1,0 MPa. 
Seguindo as especificações da NBR 12024 (ABNT, 1992c), foram confeccionados corpos-deprova com as misturas de solo-cimento-casca de arroz escolhidas, os quais foram curados durante 7 dias em câmara úmida e conservados em ambiente de laboratório até a idade de rompimento.

Chegadas as idades de 7 e 28 dias, os corpos-de-prova foram imersos em água por um período de quatro horas, sendo depois aplicados os ensaios de compressão simples e de tração na compressão diametral, segundo as normas NBR 12025 (ABNT, 1990) e NBR 7222 (ABNT, 1994).

Os corpos-de-prova foram também submetidos ao ensaio de absorção d'água aos 7 dias de idade. Esse ensaio consistiu na pesagem dos corpos-de-prova após imersão em água durante 24 horas (massa saturada), seguida de secagem em estufa a $105^{\circ} \mathrm{C}$ até constância de massa (massa seca). A diferença percentual entre as massas saturada e seca correspondeu ao valor da capacidade total de absorção d'água, calculada em base seca.

\section{RESULTADOS E DISCUSSÃO}

\section{Características das matérias-primas}

A casca de arroz, em sua condição natural, caracterizou-se como sendo material leve (massa específica aparente de $0,11 \mathrm{~g} \mathrm{~cm}^{-3}$ ) e distribuição uniforme em tamanho (83\% compreendidos entre as peneiras de $2,4 \mathrm{~mm}$ e $1,2 \mathrm{~mm}$ ). Depois de passar pelos processos de trituração, peneiramento e tratamento em solução de cal, a massa unitária da casca de arroz aumentou para $0,20 \mathrm{~g} \mathrm{~cm}^{-3}$, com aproximadamente $85 \%$ da sua massa apresentando-se com tamanho de $0,6 \mathrm{~mm}$, representando isso a uniformização da fração utilizável, a presença não-significativa de finos e o aumento de sua superfície específica para melhor adesão à mistura solo-aglomerante. Após os procedimentos aplicados à casca de arroz, essa apresentou-se com umidade próxima a 6,5\% e foi acondicionada em sacos plásticos para posterior utilização nas misturas de solo-cimento.

Os índices físicos dos solos estudados (Tabela 1) mostraram que o solo arenoso utilizado é adequado para estabilização com cimento, pois possui granulometria desuniforme, que facilita a interação entre o solo e o aglomerante, e quantidade suficiente de finos (argila + silte) que confere maior plasticidade à mistura. $\mathrm{O}$ solo argiloso apresentou grande porcentagem de finos e elevado Índice de Plasticidade (IP), o que, segundo ABCP (1985), dificulta o processo de estabilização do solo. Podese confirmar essa dificuldade nos corpos-de-prova de solo argiloso-cimento-casca, pois houve necessidade de altos teores de aglomerante para que as misturas atingissem valores de resistência mínima para utilização como componente construtivo.

TABELA 1. Caracterização física dos solos utilizados.

\begin{tabular}{ccccccccc}
\hline \multirow{2}{*}{ Solos } & \multicolumn{3}{c}{ Granulometria } & \multicolumn{3}{c}{ Índices Físicos } & \multicolumn{3}{c}{ Classificação } \\
\cline { 2 - 9 } & areia & Silte & argila & $\gamma_{\mathrm{s}}$ & LL & LP & IP & AASHTO \\
\hline Arenoso & $72,1 \%$ & $18,9 \%$ & $8,9 \%$ & $2,67 \mathrm{~g} \mathrm{~cm}^{-3}$ & $\mathrm{NP}$ & $\mathrm{NP}$ & $\mathrm{NP}$ & $\mathrm{A}_{2-4}$ \\
\hline Argiloso & $27,6 \%$ & $34,5 \%$ & $37,9 \%$ & $3,06 \mathrm{~g} \mathrm{~cm}^{-3}$ & $43,6 \%$ & $32,2 \%$ & $11,4 \%$ & $\mathrm{~A}_{7-5}$ \\
\hline
\end{tabular}

LP - limite de plasticidade; LL - limite de liquidez; IP - índice de plasticidade; $\gamma_{\mathrm{s}}$ - massa específica dos sólidos.

\section{Estudo de dosagem das misturas de solo-cimento-casca de arroz}

Nas Tabelas 2 e 3, apresentam-se os valores de umidade ótima $\left(\mathrm{h}_{\mathrm{ot}}\right)$ de cada mistura de solocimento-casca de arroz, determinados no ensaio de compactação normal de Proctor. Nas Figuras 1; 2 e 3, estão mostrados os valores de resistência à compressão simples, aos 7 dias, e respectivos valores de massa específica aparente seca máxima dos corpos-de-prova de solo-cimento-casca de arroz. 
TABELA 2. Valores de umidade ótima (\%) das misturas de solo-cimento-casca de arroz.

\begin{tabular}{|c|c|c|c|c|}
\hline \multirow{3}{*}{$\begin{array}{c}\text { Umidade Ótima do Solo-Cimento- } \\
\text { Casca } \\
(\%)\end{array}$} & \multicolumn{4}{|c|}{ Tipo de Solo } \\
\hline & \multicolumn{2}{|c|}{ Arenoso } & \multicolumn{2}{|c|}{ Argiloso } \\
\hline & Média & $\mathrm{DPM}^{*}$ & Média & $\mathrm{DPM}^{*}$ \\
\hline Testemunha solo (test.) & 13,50 & 0,20 & 26,50 & 0,50 \\
\hline $\mathrm{C}_{1}-8 \%(100 \%$ cimento $+0 \%$ casca $)$ & 13,40 & 0,10 & 25,95 & 0,40 \\
\hline $\mathrm{C}_{2}-8 \%$ (90\% cimento $+10 \%$ casca) & 13,82 & 0,08 & 26,37 & 0,06 \\
\hline $\mathrm{C}_{3}-8 \%$ (80\% cimento $+20 \%$ casca $)$ & 14,10 & 0,17 & 27,37 & 0,15 \\
\hline $\mathrm{C}_{4}-8 \%$ (70\% cimento $+30 \%$ casca) & 14,57 & 0,25 & 28,33 & 0,12 \\
\hline $\mathrm{C}_{5}-8 \%$ (60\% cimento $+40 \%$ casca $)$ & 15,67 & 0,29 & 28,38 & 0,13 \\
\hline $\mathrm{C}_{6^{-}} 12 \%$ (100\% cimento $+0 \%$ casca $)$ & 13,45 & 0,38 & 25,92 & 0,08 \\
\hline $\mathrm{C}_{7^{-}} 12 \%$ (90\% cimento $+10 \%$ casca) & 14,02 & 0,23 & 27,13 & 0,21 \\
\hline $\mathrm{C}_{8^{-}} 12 \%$ (80\% cimento $+20 \%$ casca) & 14,83 & 0,12 & 27,67 & 0,12 \\
\hline $\mathrm{C}_{9^{-}}-12 \%$ (70\% cimento $+30 \%$ casca) & 15,63 & 0,31 & 27,67 & 0,47 \\
\hline $\mathrm{C}_{10^{-}} 12 \%$ (60\% cimento $+40 \%$ casca) & 16,57 & 0,21 & 28,17 & 0,15 \\
\hline
\end{tabular}

TABELA 3. Valores de umidade ótima (\%) das misturas de solo argiloso-cimento-casca de arroz.

\begin{tabular}{|c|c|c|}
\hline \multirow{2}{*}{$\begin{array}{l}\text { Umidade Ótima do Solo-Cimento-Casca } \\
\qquad(\%)\end{array}$} & \multicolumn{2}{|c|}{ Solo Argiloso } \\
\hline & Média & $\mathrm{DPM}^{*}$ \\
\hline Testemunha solo & 13,50 & 0,20 \\
\hline $\mathrm{C}_{21}-14 \%$ (100\% cimento $+0 \%$ casca $)$ & 24,20 & 0,10 \\
\hline $\mathrm{C}_{22}-14 \%$ (90\% cimento $+10 \%$ casca $)$ & 25,63 & 0,06 \\
\hline $\mathrm{C}_{23^{-}} 14 \%$ (80\% cimento $+20 \%$ casca) & 26,10 & 0,10 \\
\hline $\mathrm{C}_{24}-18 \%$ ( $100 \%$ cimento $+0 \%$ casca $)$ & 24,73 & 0,12 \\
\hline $\mathrm{C}_{25^{-}} 18 \%$ (90\% cimento $+10 \%$ casca $)$ & 26,10 & 0,17 \\
\hline $\mathrm{C}_{26}-18 \%$ ( $80 \%$ cimento $+20 \%$ casca) & 26,70 & 0,10 \\
\hline
\end{tabular}

*DPM - desvio-padrão médio.

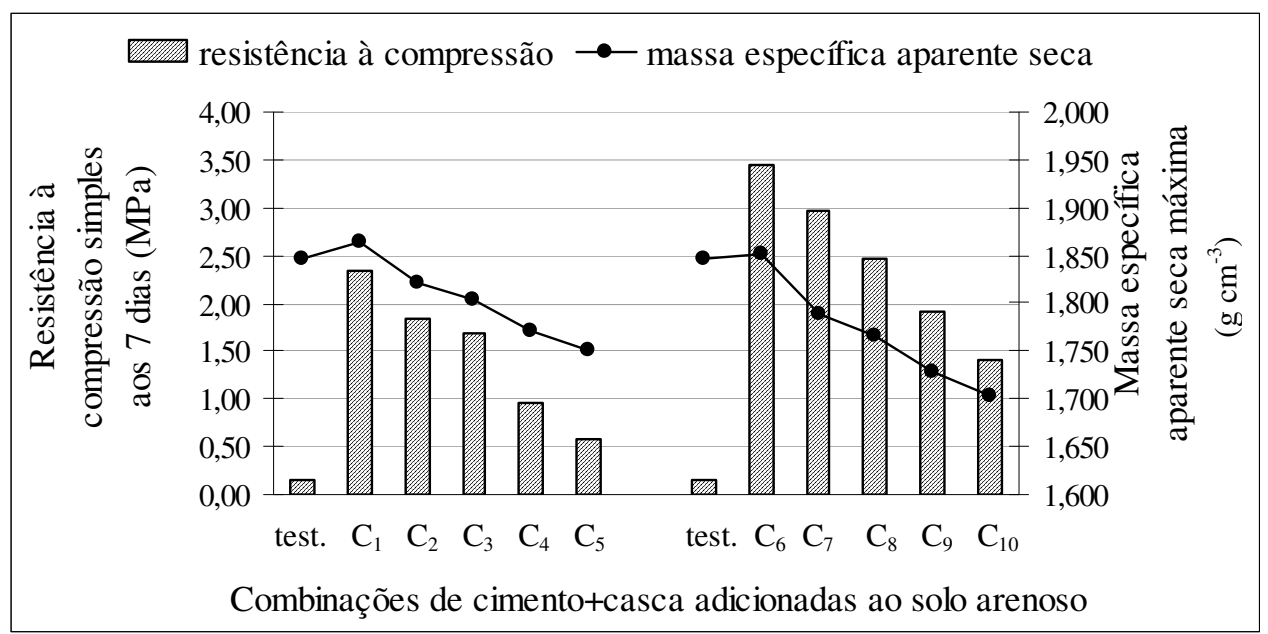

FIGURA 1. Valores de resistência à compressão simples e de massa específica aparente seca máxima dos corpos-de-prova de solo arenoso adicionados de combinações de cimento + casca. 


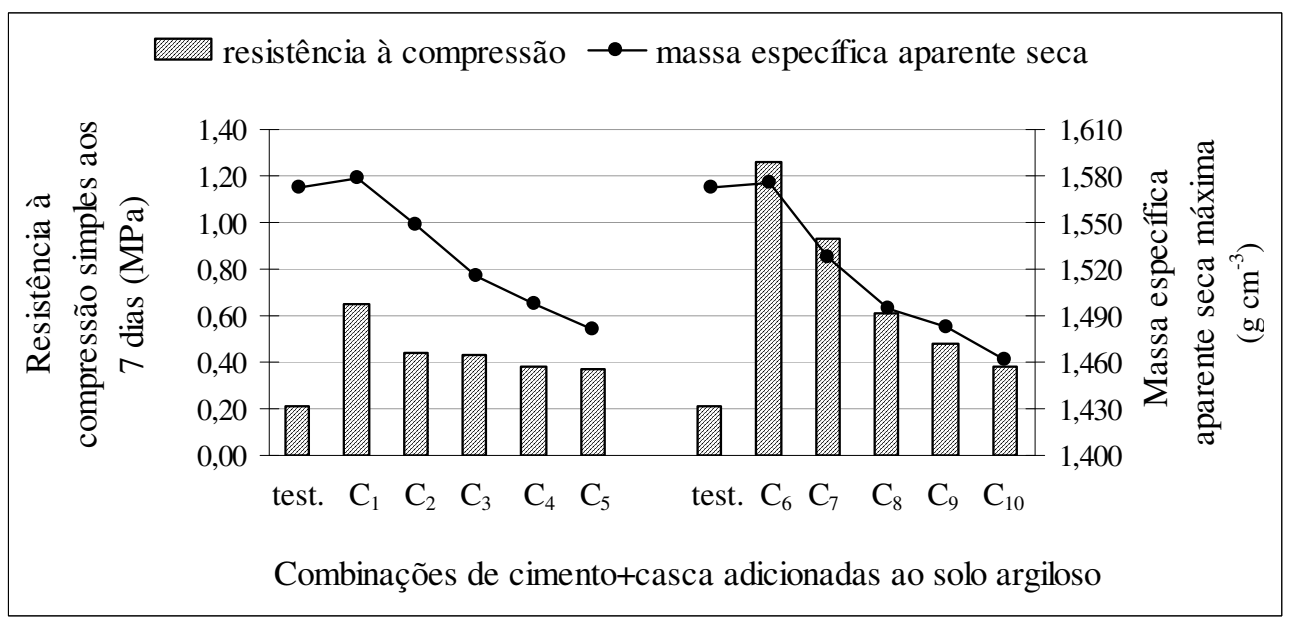

FIGURA 2. Valores de resistência à compressão simples e de massa específica aparente seca máxima dos corpos-de-prova de solo argiloso adicionados de combinações de cimento+casca.

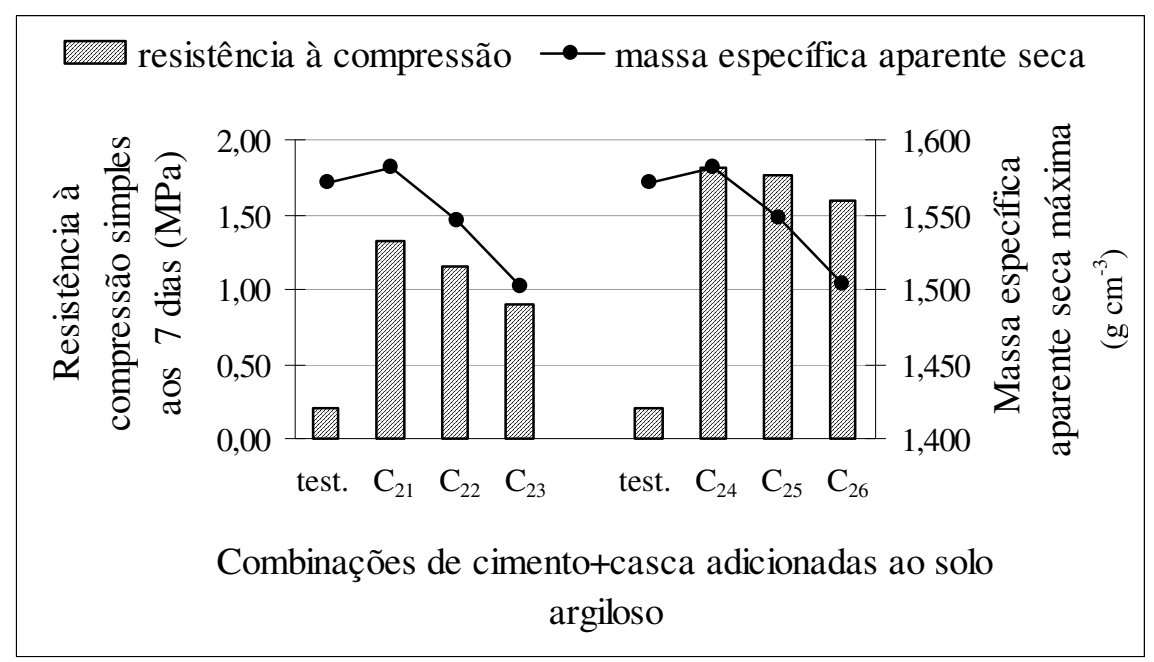

FIGURA 3. Valores de resistência à compressão simples e de massa específica aparente seca dos corpos-de-prova de solo argiloso adicionados de outras combinações de cimento + casca.

Pode-se notar, nas Figuras 1 e 2, que os valores de resistência à compressão simples dos corposde-prova de solo arenoso-cimento-casca e de solo argiloso-cimento-casca apresentaram comportamento semelhante aos valores de massa específica aparente seca máxima $\left(\gamma_{\max }\right)$. Ao se adicionarem as combinações com o teor de $100 \%$ de cimento e $0 \%$ de casca de arroz aos solos arenoso e argiloso, elevaram-se os valores de resistência e $\gamma_{\max }$. Por outro lado, ao se adicionarem aos solos as combinações que continham casca de arroz, os valores de resistência e de $\gamma_{\max }$ diminuíram, tanto mais quanto maior o teor de casca incorporada à mistura. Essa semelhança de comportamento pode ser explicada pela relação existente entre as propriedades físico-mecânicas do sistema solo-aglomerante compactado com a densidade, pois, quanto menos vazios no sistema, melhor a interação entre soloaditivo e, conseqüentemente, maiores as resistências alcançadas.

A análise estatística dos dados das Figuras 1 e 2 revelou aumento não-significativo da $\gamma_{\max }$ dos solos que incorporaram as combinações com o teor de $100 \%$ de cimento. Houve diminuição significativa da $\gamma_{\max }$ com o aumento do teor de casca de arroz. Ocorreram aumentos significativos da umidade ótima, quanto maiores as adições de casca de arroz (Tabelas 2 e 3 ). 
Quanto aos valores preliminares de resistência à compressão simples, o melhor resultado foi para o solo arenoso adicionado da combinação $\mathrm{C}_{6}(3,45 \mathrm{MPa})$. Os piores resultados foram apresentados pelas testemunhas e pelo solo argiloso adicionado das combinações $\mathrm{C}_{4}(0,38 \mathrm{MPa}), \mathrm{C}_{5}(0,36 \mathrm{MPa}) \mathrm{e}$ $\mathrm{C}_{10}(0,38 \mathrm{MPa})$ (Figura 1).

Analisando o solo arenoso adicionado do teor de $8 \%$ da combinação de cimento + casca (Figura 1), apenas as combinações $\mathrm{C}_{1}, \mathrm{C}_{2}$ e $\mathrm{C}_{3}$ apresentaram resistência à compressão maior que 1,5 $\mathrm{MPa}$. Para o teor de $12 \%$ da combinação cimento + casca, tal fato ocorreu com as combinações $\mathrm{C}_{6}, \mathrm{C}_{7}, \mathrm{C}_{8}$ e $\mathrm{C}_{9}$. Estatisticamente, não houve diferenças significativas entre as combinações $C_{2}$ e $C_{3}$ e entre as combinações $\mathrm{C}_{7}$ e $\mathrm{C}_{8}$. Pelos critérios de maior teor de casca aliado ao valor mínimo de resistência de 1,5 $\mathrm{MPa}$, as primeiras misturas escolhidas para fins de caracterização físico-mecânica foram:

$\mathrm{T}_{1}$ - testemunha solo arenoso

$\mathrm{T}_{3}-$ arenoso $+8 \%(80 \%$ cimento $+20 \%$ casca $)$

$\mathrm{T}_{5}$ - arenoso $+12 \%$ (80\% cimento $+20 \%$ casca)

$$
\begin{aligned}
& \mathrm{T}_{2}-\text { arenoso }+8 \%(100 \% \text { cimento }+0 \% \text { casca }) \\
& \mathrm{T}_{4}-\text { arenoso }+12 \%(100 \% \text { cimento }+0 \% \text { casca }) \\
& \mathrm{T}_{6}-\text { arenoso }+12 \%(70 \% \text { cimento }+30 \% \text { casca })
\end{aligned}
$$

O solo argiloso adicionado do teor de $8 \%$ da combinação cimento + casca e do teor de $12 \%$ da combinação cimento + casca não alcançou o valor de resistência à compressão mínima de $1,5 \mathrm{MPa}$ (Figura 2). Portanto, mais dois teores da combinação de cimento + casca foram adotados para serem incorporados ao solo argiloso. Os teores foram $14 \%$ e $18 \%$ da combinação de cimento + casca, sendo que as variações de cimento e de casca foram de $100 \%$ de cimento com $0 \%$ de casca, e $80 \%$ de cimento com $20 \%$ de casca, em intervalos de $10 \%$. Adotou-se o incremento máximo de $20 \%$ de casca, visto que os teores de $14 \%$ e $18 \%$ da combinação cimento + casca são, por si só, elevados.

Os resultados mostrados na Figura 3 indicaram comportamentos semelhantes aos da Figura 2. Apenas o teor de $18 \%$ da combinação de cimento + casca alcançou o valor de resistência à compressão mínima de 1,5 MPa. Com base nesse resultado, as demais misturas a serem caracterizadas foram:

$\mathrm{T}_{7}$ - testemunha solo argiloso

$\mathrm{T}_{9}$ - argiloso $+18 \%(90 \%$ cimento $+10 \%$ casca $)$

$$
\begin{aligned}
& \mathrm{T}_{8}-\text { argiloso }+18 \%(100 \% \text { cimento }+0 \% \text { casca }) \\
& \mathrm{T}_{10}-\text { argiloso }+18 \%(80 \% \text { cimento }+20 \% \text { casca })
\end{aligned}
$$

\section{Caracterização físico-mecânica dos corpos-de-prova de solo-cimento-casca de arroz}

Com relação aos valores de resistência à compressão simples dos corpos-de-prova de solocimento-casca de arroz, aos 7 dias de idade (Tabela 4), o teste de Tukey mostrou que o maior valor foi apresentado pelo tratamento $\mathrm{T}_{4}$, seguido dos tratamentos $\mathrm{T}_{2}, \mathrm{~T}_{5}$ e $\mathrm{T}_{6}$, estatisticamente iguais entre si. Por outro lado, os menores valores foram alcançados pelas testemunhas e pelos tratamentos $\mathrm{T}_{3}, \mathrm{~T}_{8}, \mathrm{~T}_{9} \mathrm{e}$ $\mathrm{T}_{10}$, os quais também não apresentaram diferenças significativas entre si. Aos 28 dias de idade, tenderam ao mesmo comportamento, conferindo ao cimento maiores valores de resistência à compressão simples, e os tratamentos com maior adição de casca, os menores valores.

Os valores de resistência à tração na compressão diametral, aos 7 e aos 28 dias, apresentaram comportamento semelhante aos valores de resistência à compressão simples, sendo novamente destacados os tratamentos $\mathrm{T}_{2}, \mathrm{~T}_{4}, \mathrm{~T}_{5}$ e $\mathrm{T}_{6}$ por apresentarem melhor desempenho. Durante a execução do ensaio de tração na compressão diametral, o equipamento não apresentou escala adequada para a execução das leituras de carga de ruptura dos corpos-de-prova, o que acarretou numa considerável variabilidade dos resultados de resistência à tração na compressão diametral, num mesmo tratamento.

O desempenho mecânico dos corpos-de-prova sempre foi maior aos 28 dias do que aos 7 dias para todos os tratamentos (Tabela 4), e os valores de resistência à compressão simples aumentaram a níveis estatisticamente significativos, chegando a um valor médio de $30 \%$ de ganho de resistência para cada tratamento. Para os valores de resistência à tração na compressão diametral, apesar da tendência de aumento da resistência com a idade, a maioria dos tratamentos, aos 7 e aos 28 dias, não diferiram 
entre si. Esse aumento de resistência mecânica ocorrido nas misturas de solo-cimento-casca indica a formação, ao longo do tempo, de compostos cimentantes que melhoram as propriedades mecânicas da mistura (ABIKO, 1980). Acredita-se que o efeito de estabilização do solo com cimento foi mais significativo do que a influência negativa da casca ao sistema solo-cimento.

TABELA 4. Resistência à compressão simples (MPa) e resistência à tração na compressão diametral (MPa), aos 7 e aos 28 dias, de corpos-de-prova de solo-cimento-casca de arroz.

\begin{tabular}{|c|c|c|c|c|}
\hline \multirow{2}{*}{ Trat. } & \multicolumn{2}{|c|}{ Compressão Simples } & \multicolumn{2}{|c|}{ Compressão Diametral } \\
\hline & 7 dias & 28 dias & 7 dias & 28 dias \\
\hline $\mathrm{T}_{1}$ & $* 0,16 \pm 0,01(2,62) \mathrm{dB}$ & $0,40 \pm 0,06(7,42) \mathrm{g} \mathrm{A}$ & $0,01 \pm 0,01(20,1) \mathrm{f} B$ & $0,10 \pm 0,01(11,78)$ f $\mathrm{A}$ \\
\hline $\mathrm{T}_{2}$ & $1,90 \pm 0,06(3,27)$ b B & $2,30 \pm 0,27(11,7)$ c $\mathrm{A}$ & $0,33 \pm 0,09(26,7)$ с $\mathrm{B}$ & $0,56 \pm 0,02(3,98)$ a $A$ \\
\hline $\mathrm{T}_{3}$ & $1,26 \pm 0,04(3,21)$ с B & $1,66 \pm 0,03(1,94)$ ef $A$ & $0,20 \pm 0,02(11,1)$ de $\mathrm{B}$ & $0,32 \pm 0,03(10,31)$ c $\mathrm{A}$ \\
\hline $\mathrm{T}_{4}$ & $2,70 \pm 0,24(9,02)$ a $\mathrm{B}$ & $3,48 \pm 0,14(3,95)$ a A & $0,52 \pm 0,02(3,53)$ a A & $0,57 \pm 0,03(5,99)$ a $\mathrm{A}$ \\
\hline $\mathrm{T}_{5}$ & $2,00 \pm 0,05(2,33)$ b B & $2,81 \pm 0,05(1,95) \mathrm{b} \mathrm{A}$ & $0,41 \pm 0,01(2,25) \mathrm{b} \mathrm{A}$ & $0,43 \pm 0,01(1,46)$ b A \\
\hline $\mathrm{T}_{6}$ & $1,83 \pm 0,06(3,37)$ b B & $2,18 \pm 0,04(2,62) \mathrm{cd} A$ & $0,33 \pm 0,01(0,96)$ с A & $0,34 \pm 0,02(5,30) \mathrm{c} \mathrm{A}$ \\
\hline $\mathrm{T}_{7}$ & $0,23 \pm 0,01(1,87) \mathrm{d} B$ & $1,62 \pm 0,01(1,72)$ ef $\mathrm{A}$ & $0,04 \pm 0,01(17,6) \mathrm{f} \mathrm{B}$ & $0,25 \pm 0,01(2,62) \mathrm{d} A$ \\
\hline $\mathrm{T}_{8}$ & $1,37 \pm 0,03(2,28)$ c B & $1,94 \pm 0,26(13,3) \mathrm{de} A$ & $0,21 \pm 0,01(2,62) \mathrm{d} A$ & $0,23 \pm 0,03(14,15) \mathrm{d} A$ \\
\hline $\mathrm{T}_{9}$ & $1,36 \pm 0,05(3,46)$ с B & $1,64 \pm 0,03(1,72)$ ef $\mathrm{A}$ & $0,18 \pm 0,01(7,68) \mathrm{de} A$ & $0,20 \pm 0,01(2,88)$ de $A$ \\
\hline $\mathrm{T}_{10}$ & $1,14 \pm 0,03(3,06)$ с A & $1,40 \pm 0,02(1,48)$ f A & $0,14 \pm 0,01(2,48)$ e A & $0,14 \pm 0,01(7,68)$ ef $\mathrm{A}$ \\
\hline
\end{tabular}

*Valores médios \pm desvio-padrão (coeficiente de variação).

Em cada coluna, médias seguidas de mesma letra minúscula não diferem entre si, pelo teste de Tukey, a $5 \%$ de probabilidade. Em cada linha, médias seguidas de mesma letra maiúscula não diferem entre si, pelo de Tukey, a 5\% de probabilidade.

Os valores de resistência à compressão simples alcançados pelos corpos-de-prova de solocimento-casca, quando comparados com os resultados encontrados na etapa de estudo de dosagem, sofreram decréscimo de resistência, mas mantiveram o mesmo comportamento frente à adição das combinações de cimento-casca ao solo. Evidentemente, essa redução deveu-se ao fato da imersão dos corpos-de-prova em água antes do rompimento, o que não ocorreu na etapa do estudo de dosagem.

Quanto à absorção d'água, os menores valores foram alcançados pelos tratamentos $\mathrm{T}_{2}, \mathrm{~T}_{3}, \mathrm{~T}_{4}, \mathrm{~T}_{5}$ e $\mathrm{T}_{6}$, os quais não diferiram ente si. Os tratamentos $\mathrm{T}_{8}, \mathrm{~T}_{9}$ e $\mathrm{T}_{10}$, ou seja, tratamentos com o solo argiloso, apresentaram valores de absorção d'água elevados. Pode-se notar, pela Figura 4, que, tanto para as misturas com solo arenoso como para as misturas com solo argiloso, os valores de absorção d'água tenderam a aumentar conforme o aumento de casca de arroz incorporada à mistura.

Os valores de massa específica aparente seca comportaram-se de maneira inversa aos valores de absorção d'água, ou seja, quanto menor a massa específica aparente seca, maior a capacidade de absorver água. Essa relação pode ser explicada pela falta de interação entre o sistema solo-cimento e a casca, mostrando que maiores volumes de vazios são incorporados ao sistema quanto maior for a adição de casca. O ensaio de absorção d'água não foi aplicado às testemunhas dos solos.

Em termos de resistência à compressão simples, somente os tratamentos $\mathrm{T}_{4}$ e $\mathrm{T}_{5}$, ou seja, a mistura de solo arenoso $+12 \%$ de cimento e a mistura de solo arenoso $+12 \%$ da combinação (de $80 \%$ de cimento $+20 \%$ de casca de arroz) apresentaram potencialidade para atender às especificações da NBR 8492 (ABNT, 1992d), empregada para tijolos prensados de solo-cimento. Essa norma estabelece, como mínimo, o valor médio de 2,0 MPa e nenhum valor inferior a 1,7 MPa aos 7 dias de idade. Em relação à capacidade de absorção d'água, somente os tratamentos com solo arenoso apresentaram potencialidade para atender às especificações da NBR 8492 (ABNT, 1992d), que estabelecem, como máximo, o valor médio de $20 \%$ e nenhum superior a $22 \%$. 
$\dddot{Z}$ absorção total $\longrightarrow$ massa específica aparente seca

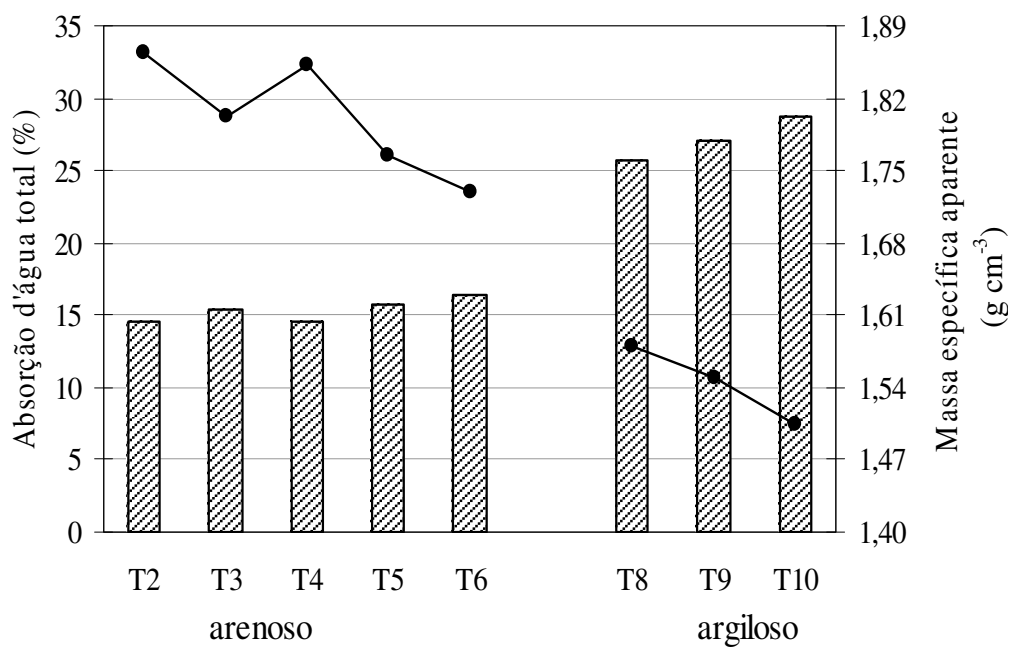

FIGURA 4. Capacidade de absorção d'água total e valores de massa específica aparente seca dos corpos-de-prova de solo-cimento-casca de arroz.

\section{CONCLUSÕES}

Os valores de massa específica aparente seca máxima, de resistência à compressão simples e de tração na compressão diametral das composições de solo-cimento-casca de arroz, decresceram com o aumento do teor de casca de arroz. Já os valores de umidade ótima e absorção d'água elevaram-se, conforme o acréscimo do teor de casca de arroz. Para todos os tratamentos, os valores de resistência mecânica foram sempre maiores aos 28 dias do que aos 7 dias, evidenciando a tendência de aumento de resistência ao longo do tempo.

Os resultados promissores para a confecção de componentes construtivos foram expressos pelos tratamentos com solo arenoso, sendo destacada a adição ao solo de $12 \%$ de cimento e a adição de $12 \%$ da combinação (de $80 \%$ de cimento $+20 \%$ de casca).

\section{REFERÊNCIAS}

ABIKO, A.K. Tecnologias apropriadas: tijolos e paredes monolíticas de solo-cimento. $115 \mathrm{p}$. Dissertação (Mestrado em Construção Civil) - Escola Politécnica, Universidade de São Paulo, São Paulo, 1980.

ASSOCIAÇÃO BRASILEIRA DE CIMENTO PORTLAND - ABCP. Fabricação de tijolos de solocimento com a utilização de prensas manuais. São Paulo, 1985. 4 p. (Boletim Técnico, 111)

ASSOCIAÇÃO BRASILEIRA DE NORMAS TÉCNICAS - ABNT. NBR 5735. Cimento Portland de alto forno. Rio de Janeiro, 1991. 10 p.

NBR 6459. Solo - determinação do limite de liquidez. Rio de Janeiro, 1984b. 6 p.

NBR 650. Determinação da massa específica. Rio de Janeiro, 1982. 2 p.

NBR 7175. Cal hidratada para argamassas. Rio de Janeiro, 1992a. 5 p.

. NBR 7180. Solo - determinação do limite de plasticidade. Rio de Janeiro, 1984c. 3 p.

. NBR 7181. Solo - análise granulométrica. Rio de Janeiro, 1984a. 13 p.

. NBR 7222. Argamassa e concreto - determinação da resistência à tração por compressão

diametral de corpos-de-prova cilíndricos. Rio de Janeiro, 1994. 5 p. 
. NBR 8492.Tijolo maciço de solo-cimento - determinação da resistência à compressão e da absorção d'água. Rio de Janeiro, 1992d. 8 p. . NBR 12023. Solo-cimento - ensaio de compactação. Rio de Janeiro, 1992b. 9 p.

_ NBR 12024. Solo-cimento - moldagem e cura de corpos-de-prova. Rio de Janeiro, 1992c. 8 p.

_. NBR 12025. Solo-cimento - ensaio de compressão simples de corpos-de-prova cilíndricos. Rio de Janeiro, 1990. 3 p.

FERREIRA, R.C. Desempenho físico-mecânico e propriedades termofísicas de tijolos e minipainéis de terra crua tratada com aditivos químicos. 204 f. Tese (Doutorado em Construções Rurais) Faculdade de Engenharia Agrícola, Universidade Estadual de Campinas, Campinas, 2003.

NEVES, C.M.M. Desempenho de paredes - procedimento adotado para paredes monolíticas de solocimento. In: SIMPÓSIO DE DESEMPENHO DE MATERIAIS E COMPONENTES DE CONSTRUÇÃO CIVIL, 1., 1988, Florianópolis. Anais...Florianópolis: [s.n.], 1988. p.58-64.

PICCHI, F.A.; CINCOTTO, M.A.; BARROS, J.M.C. Tijolos de solo-cal. Revista A Construção, São Paulo, p.93-8, 1990. (Tecnologia de Edificações IPT/Ded90).

SILVEIRA, A.; FERREIRA, A.A.; DAL MOLIN, D.C.C. A cinza da casca de arroz como adição mineral. In: WORKSHOP RECICLAGEM E REUTILIZAÇÃO DE RESÍDUOS COMO

MATERIAIS DE CONSTRUÇÃO CIVIL, 1., 1996, São Paulo. Anais... São Paulo: [s.n.], 1996. p.3945.

ZUCCO, L.L. Estudo da viabilidade de fabricação de placas de compósitos à base de cimento e casca de arroz. 118 f. Dissertação (Mestrado em Construções Rurais) - Faculdade de Engenharia Agrícola, Universidade Estadual de Campinas, Campinas, 1999. 